\title{
ANALISIS PENGENDALIAN PERSEDIAAN DALAM HUBUNGANNYA DENGAN EFISIENSI BIAYA DI PT. HITEK INDO MULIA
}

\author{
Decky Antony Kifta \\ Program Magister Manajemen, Universitas Riau Kepulauan, Jalan Batu Aji Baru No. 99, Kota Batam \\ email: deckyantoni@gmail.com
}

\begin{abstract}
ABSTRAK
Studi ini bertujuan untuk melihat pengendalian persediaan dalam hubungannya dengan efisiensi biaya di PT Hitek Indo Mulia. Dengan demikian, perusahaan, PT Hitek Indo Mulia sebagai tempat penelitian dan sumber data guna mendukung penulisan jurnal ini. Adapun persediaan yang dijadikan bahan penelitian adalah persediaan film radiografi, sebagai persedian yang utama bagi perusahaan dan alat analisis yang digunakan untuk menganalisis pengendalian persediaan berhubungan dengan efisiensi biaya dan peramalan, alat-alat tersebut adalah Economic Order Quantity (EOQ), Re-order Point (ROP), dan Total Inventory Cost (TIC). Dari hasil perhitungan terlihat bahwa dengan menggunakan metode Economic Order Quantity maka akan terjadi penghematan biaya sebesar Rp. 1.704.799,24 dengan pemesanan kembali sebanyak 6 kali. Hal ini dimaksudkan untuk memberikan arahan bagi perusahaan untuk menggunakan metode perhitungan dan pengukuran ini, dan bukan mengandalkan pada insting atau intuisi semata. Sehingga persediaan film (grafts) radiografi tidak menumpuk tetapi terus digunakan dan memberikan manfaat bagi perusahaan.
\end{abstract}

KATA KUNCI:

Pengendalian Persediaan, Efisiensi biaya, EOQ, ROP, TIC.

\begin{abstract}
This study is intended to formalize how to control goods inventory in relation with the cost efficiency of inventory at PT Hitek Indo Mulia. The company, PT Hitek Indo Mulia, is the venue of the research and source of data for the researcher to write this jurnal. The inventory observed in this research is Radiography films as the main inventory of the company and the analysis tools used in this inventory control is related to cost eficient and forecasting i.e. Economic Order Quantity (EOQ), Re-order Point (ROP), and Total Inventory Cost (TIC). From the calculation it was shown that there was cost saving upto Rp. 1.704.799,24 and with 6 (six) times of re-order point. This is to give economical guidance to the company to use this calculation or measures, and they shall not depend on guessing or intuation. By implementing this theory we will not see that radiography films (grafts) are piled up in the store but they are continuously used up and give value to the company.
\end{abstract}

\section{KEYWORDS:}

Inventory Control, Cost Efficient, EOQ, ROP, TIC.

\section{PENDAHULUAN}

Pengendalian persediaan bahan baku merupakan hal yang sangat penting, sebab bahan baku merupakan salah satu faktor yang menjamin kelancaran proses produksi dan memungkinkan penyelesaian produksi sesuai jadwal yang direncanakan dan yang akhirnya memberikan kepuasan kepada pelanggan. Ketidaklancaran persediaan akan berdampak buruk bagi produksi dan mengakibatkan ketidakpuasan pelanggan dan tentunya berujung pada keluhan pelanggan bahkan klaim warranty. PT Hitek Indo Mulia merupakan perusahaan modal dalam negeri yang telah berdiri sejak tahun 2004. Perusahaan yang beroperasi sebagai penyedia jasa berupa pekerjaan non-destructive testing (NDT), yaitu kegiatan inspeksi pengelasan yang sangat dibutuhkan oleh perusahaan-perusahaan fabrikasi dan galangan kapal 
di Pulau Batam. PT Hitek Indo Mulia telah mempunyai berbagai macam sertifikasi baik internasional maupun nasional, seperti sertifikat ISO 9001, ISO 17020, Surat Kemampuan Usaha (SKU) dari Dirjen Migas, dan beberapa sertifikat lainnya.

Salah satu bahan utama yang dibutuhkan perusahaan untuk melaksanakan tugas inspeksinya adalah film radiography, film tadi digunakan hampir setiap harinya oleh perusahaan dan film ini merupakan produk import yang berasal dari Jepang ataupun Amerika. Film radiography ini merupakan barang persediaan yang bernilai besar dan merupakan kebutuhan utama operasional perusahaan. Merek-merek dagang film radiography ini adalah seperti Kodak, Fuji dan lain-lain sebagainya. Jenis-jenis film radiography yang digunakan adalah sebagai berikut:

\section{KAJIAN PUSTAKA}

Inventory atau persediaan menurut Schroeder (1995, h.4) adalah stok barang yang digunakan untuk memudahkan produksi atau untuk memuaskan permintaan pelanggan. Walaupun beberapa orang menganggap bahwa persediaan ini adalah sumber daya yang menganggur namun persediaan tersebut memiliki nilai ekonomis yang potensial dan bahkan kadang bernilai tidak murah. Mungkin saja kita menganggap bahwa bahan baku yang menganggur sebagai sediaan atau stok, tetapi sebenarnya lebih jauh lagi itu dapat dianggap sebagai kapasitas. Menurut Herjanto (2008, h.237) persediaan adalah bahan atau barang yang disimpan dan akan digunakan untuk memenuhi tujuan tertentu, misalnya untuk tujuan produksi atau perakitan, atau untuk suku cadang dari suatu peralatan atau mesin.

Persediaan juga merupakan aktiva yang mencakup semua barang milik suatu perusahaan yang dapat digunakan atau dijual dalam suatu waktu proses atau waktu produksi, dan dapat juga sebagai produk dalam proses atau WIP (work in process), sebagaimana yang dijelaskan oleh Rangkuti (2007, h.14). Bahkan menurut Johns dan Harding (1996, h.71), bahwa persediaan adalah suatu bentuk keputusan investasi yang penting, sehingga dalam penanganannya memerlukan sikap yang hati-hati. Persediaan juga didefinisikan oleh Kusuma (2009, h.132) sebagai barang yang disimpan untuk digunakan atau dijual pada saat-saat mendatang. Selanjutnya Prawirosentono (2005) mendefinisikan bahwa persediaan adalah kekayaan lancar yang ada di perusahaan dalam bentuk persediaan bahan mentah (raw material), barang setengah jadi (work in process), dan barang jadi (finished goods).

Herjanto (2009) mengemukakan beberapa fungsi persediaan dalam memenuhi kebutuhan perusahaan sebagai berikut:

1. Menghilangkan risiko keterlambatan pengiriman bahan baku atau barang yang dibutuhkan perusahaan.

2. Menghilangkan risiko jika material yang dipesan tidak baik sehingga harus dikembalikan.

3. Menghilangkan risiko terhadap kenaikan harga barang atau inflasi.

4. Untuk menyimpan bahan baku yang dihasilkan secara musiman sehingga perusahaan tidak akan kesulitan jika bahan itu tidak tersedia di pasaran.

5. Mendapatkan keuntungan dari pembelian dari pembelian berdasarkan diskon kuantitas.

6. Memberikan pelayanan kepada pelanggan dengan tersedianya barang yang diperlukan.

Menentukan pesanan persediaan adalah dengan menentukan berapa banyak jumlah persediaan yang dibutuhkan perusahaan dalam menjalankan kegiatannya. Untuk itu diperlukan metode EOQ (Economic Order Quantity) agar dapat menentukan kuantitas persediaan yang ekonomis. Menurut Carter (2009, h.314), Kuantitas Pemesanan Ekonomis 
(Economic Order Quantity - EOQ) adalah jumlah persediaan yang dipesan pada suatu waktu yang meminimalkan biaya persediaan tahunan.

Perhitungan EOQ menurut Heizer, Render (2010, h.94), yaitu:

EOQ atau $\mathrm{Q}=\sqrt{\frac{2 D S}{H}}$

Keterangan:

$\mathrm{Q}=$ Jumlah optimum unit per pesanan

$\mathrm{D}=$ Permintaan tahunan dalam unit

$\mathrm{S}=$ Biaya pemesanan untuk setiap pesanan

$\mathrm{H}=$ Biaya penyimpanan per unit per tahun

Menurut Assauri (2004, h.186) persediaan penyelamat (Safety Stock) adalah persediaan tambahan yang diadakan untuk melindungi atau menjaga kemungkinan terjadinya kekurangan bahan (stock out). Dalam menentukan biaya persediaan penyelamat (Safety Stock) digunakan analisis statistik, yaitu dengan mempertimbangkan penyimpanganpenyimpangan yang telah terjadi antara perkiraan pemakaian bahan baku dengan pemakaian sebenarnya, sehingga diketahui standar deviasinya.

Adapun rumus standar deviasi adalah sebagai berikut:

$\mathrm{SD}=\sqrt{\frac{\sum(X-\bar{X})^{2}}{N}}$

Keterangan :

$\mathrm{SD}=$ Standar Deviasi

$\mathrm{X}=$ Pemakaian sesungguhnya

$\bar{X}=$ Perkiraan Pemakaian

$\mathrm{N}=$ Jumlah Data

Menurut Heizer, Render (2010, h.98) juga bahwa tingkat pemesanan kembali atau $R e$ order Point (ROP) adalah suatu titik atau batas dari jumlah persediaan yang ada pada suatu saat dimana pemesanan harus diadakan kembali. Cara menghitung titik pemesanan kembali (re-order point) adalah sebagai berikut:

$\mathbf{R O P}=(\mathrm{AU} x \mathrm{LT})+\mathrm{SS}$

Keterangan:

ROP $=$ Re-order Point $($ Titik Pemesanan Kembali

AU $=$ Average use (pemakaian rata-rata dalam satuan waktu tertentu

LT = Lead Time (waktu tenggang/produksi)

SS $\quad$ Safety Stock (persediaan pengaman)

Total Inventory Cost (TIC) atau total biaya persediaan merupakan penjumlahan dari biaya simpan dan biaya pesan. TIC minimum akan tercapai pada saat biaya simpan sama dengan biaya pesan. Pada saat total biaya persediaan minimum, maka jumlah pesanan tersebut dapat dikatakan sebagai jumlah pesanan yang paling ekonomis atau EOQ. Untuk menentukan total biaya persediaan digunakan rumus sebagai berikut:

$\mathbf{T I C}=\frac{D}{Q} S+\frac{Q}{2} H$

Keterangan:

TIC = Total Biaya Persediaan (Total Inventory Cost)

$\mathrm{Q}=$ Jumlah barang setiap pemesanan

$\mathrm{D}=$ Permintaan tahunan barang persediaan (dalam unit)

$\mathrm{S}=$ Biaya pemesanan untuk setiap pemesanan

$\mathrm{H}=$ Biaya penyimpanan per unit 


\section{METODE PENELITIAN}

Pendekatan penelitian yang digunakan dalam penelitian ini adalah pendekatan kualitatif dengan cara melakukan observasi langsung, dengan wawancara dan mengumpulkan data-data berupa dokumen yang berhubungan dengan sistem pengendalian persediaan perusahaan, dalam hal ini, PT Hitek Indo Mulia.

Subjek penelitian adalah PT. Hitek Indo Mulia dan sebagai objek adalah film radiografi sebagai persediaan yang penting dalam operasi usaha perusahaan, yang bila tidak dikontrol pengendaliannya dapat mengakibatkan kekurangan stok atau bahkan kelebihan stok.

Dalam penelitian ini juga diperlukan informan-informan yang kompeten yang dapat memberikan informasi yang baik dan akurat. Informan-informan ini merupakan karyawan perusahaan yang ditunjuk untuk membantu penulis dalam melakukan penelitian di sana.

Data yang digunakan dalam penelitian ini ada yang bersifat primer dan ada pula yang sekunder. Data primer didapat dari hasil wawancara dengan pihak informan dari perusahaan baik itu karyawan atau level manajer. Sedangkan data sekunder yang digunakan adalah datadata berupa laporan dan dokumen perusahaan dan data-data lain yang berhubungan dengan penelitian. Dalam penelitian ini juga peneliti melakukan observasi langsung, melakukan wawancara dan mengumpulkan data berupa laporan-laporan dan dokumen yang berkaitan dengan penelitian.

Analisis yang digunakan dalam penelitian ini adalah analisis data deskriptif yaitu dengan melakukan pengumpulan data, menganalisis data, serta mengambil kesimpulan dari hasil penelitian yang sudah dilakukan yang berkaitan dengan pengendalian persediaan.

\section{HASIL DAN PEMBAHASAN}

\section{Gambaran Umum Perusahaan}

Perusahaan PT Hitek Indo Mulia di Batam didirikan oleh Bapak H. Raden Erwin pada tahun 2004, perusahaan ini sudah mendapat pengesahan dari Direktorat Jendral Minyak dan Gas (Migas). Sejak awal perusahaan telah bergerak dalam bidang jasa inspeksi teknik dan kemudian menjadi anggota dari Asosiasi Perusahaan Inspeksi Teknik Indonesia (APITINDO). Bapak Erwin pada saat itu dengan modal sebesar Rp. 50.000.000,- membeli peralatan radiografi (X-ray) dan bahan baku seperti film radiografi, serta mempekerjakan 10 orang untuk memulai usahanya. Dari tahun ke tahun perusahaan mengalami perkembangan dan pada tahun 2010 perusahaan berhasil mengembangkan bisnisnya ke daerah-daerah lain seperti Pekanbaru, Palembang dan Cilegon. Pada tahun 2012 perusahaan menambah modalnya yaitu dari modal sendiri sebesar Rp. 100.000.000 dan dari pinjaman bank sebesar 200.000.000,-

Kesuksesan Bapak Erwin dalam mengelola perusahaannya bukannya tidak mengalami hambatan, pada tahun 2015 perusahaan mengalami kemunduran yang diakibatkan sedikitnya proyek-proyek di bidang Migas yang beroperasi sehingga mengakibatkan dampak penurunan aktivitas perusahaan. Namun setelah tahun 2017 perusahaan mulai bergerak maju lagi dan sekarang ini perusahaan PT. Hitek Indo Mulia mempunyai lebih dari 30 orang tenaga pekerja.

Adapun tujuan didirikannya perusahaan tersebut menurut Bapak Erwin adalah dengan dua tujuan yaitu tujuan umum dan tujuan khusus.

Tujuan umum adalah:

a) Memenuhi kebutuhan, memberi kepuasan dan pelayanan yang baik kepada konsumen.

b) Membantu pemerintah menciptakan lapangan pekerjaan terutama di bidang Migas.

c) Meningkatkan kesejahteraan masyarakat

Tujuan khusus adalah memperoleh keuntungan yang optimum yang digunakan untuk sumber penghasilan perusahaan guna kelangsungan hidup perusahaan.

Di bawah ini adalah gambar dari jenis-jenis film radiografi dan kemasannya (Gambar 1). 

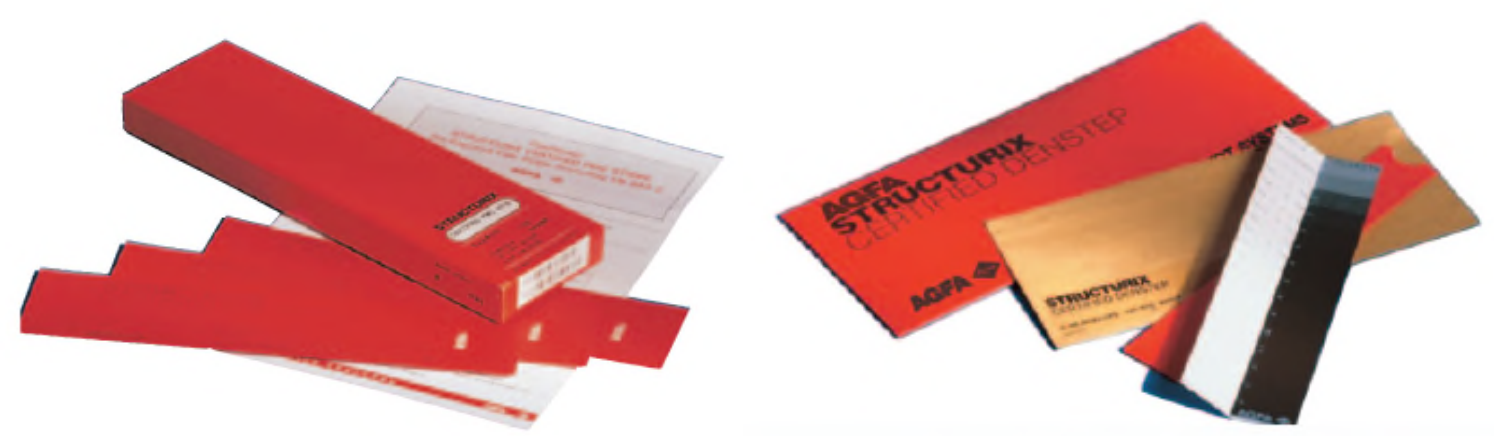

\section{Pembahasan}

Gambar 1. Jenis-jenis film radiografi dan kemasannya

\section{Kondisi Sekarang}

a) Kebutuhan Bahan Baku

Selama ini kebutuhan bahan baku berupa film radiografi diperoleh dari beberapa pemasok lokal maupun luar negeri, kebijakan pengadaan bahan baku dilakukan sesuai dengan permintaan pelanggan (proyek). Tabel 1 di bawah memberikan gambaran tentang jumlah kebutuhan film radiografi dalam tiap bulan di tahun 2017.

Tabel 1. Jumlah Film yang dibutuhkan di tahun 2017

\begin{tabular}{|c|l|c|}
\hline No & \multicolumn{1}{|c|}{ Bulan } & $\begin{array}{c}\text { Film yang dibutuhkan } \\
\text { (lembar) }\end{array}$ \\
\hline 1 & Januari & 331 \\
\hline 2 & Februari & 1292 \\
\hline 3 & Maret & 584 \\
\hline 4 & April & 1056 \\
\hline 5 & Mei & 987 \\
\hline 6 & Juni & 211 \\
\hline 7 & Juli & 112 \\
\hline 8 & Agustus & 413 \\
\hline 9 & September & 148 \\
\hline 10 & Oktober & 259 \\
\hline 11 & November & 673 \\
\hline 12 & Desember & 725 \\
\hline & Jumlah & 6791 \\
\hline
\end{tabular}

b) Pembelian Bahan Baku

Perusahaan melakukan pembelian secara tradisional yaitu setiap bulan sekali, maka ratarata jumlah pembelian film radiografi setiap pembelian atau pemesanannya sebagai berikut:

$$
\begin{aligned}
& =\frac{\text { Total Kebutuhan Film Radiografi }}{\text { Frekuensi pemesanan dalam setahun }} \\
& =\frac{6791}{12}=565,92(\text { dibulatkan menjadi } 566 \text { lembar film) }
\end{aligned}
$$

Biaya pemesanan yang dibayarkan perusahaan adalah: biaya telepon dan faksimil, biaya administrasi dan biaya transportasi, dengan rincian sebagai berikut (Tabel 2). 
Tabel 2. Biaya Pemesanan Film Radiografi

\begin{tabular}{|c|l|c|}
\hline No & \multicolumn{1}{|c|}{ Uraian Biaya } & Besaran Biaya (Rp) \\
\hline 1 & $\begin{array}{l}\text { Biaya telepon dan } \\
\text { faksimil }\end{array}$ & 2.150 .000 \\
\hline 2 & Biaya administrasi & 2.850 .000 \\
\hline 3 & Biaya transportasi & 1.450 .000 \\
\hline & Jumlah & 6.450 .000 \\
\hline
\end{tabular}

c) Biaya Pemesanan

Untuk menghitung besarnya biaya pemesanan untuk sekali pesan maka dapat dihitung dengan rumus:

$$
\begin{aligned}
& =\frac{\text { Total Biaya Pemesanan }}{\text { Frekuensi Pemesanan dalam setahun }} \\
& =\frac{R p 6.450 .000}{12}=\mathrm{Rp} 537.500
\end{aligned}
$$

Jadi besarnya biaya satu kali pesan pada pemasok maka perusahaan harus mengeluarkan biaya sebesar Rp 537.500,-

d) Biaya Penyimpanan

Biaya-biaya yang dikeluarkan perusahaan karena perusahaan melakukan penyimpanan dan pengadaan persediaan bahan baku (film radiografi), maka perincian biaya tersebut adalah: Biaya listrik (lampu dan AC), biaya pemeliharaan gudang penyimpanan (kontainer), biaya tenaga kerja. Di bawah ini adalah tabulasi masing-masing biaya yang dikeluarkan untuk penyimpanan barang persediaan selama setahun (Tabel 3).

Tabel 3. Biaya Penyimpanan Film Radiografi

\begin{tabular}{|c|l|c|}
\hline No & Uraian Biaya & Besaran Biaya (Rp) \\
\hline 1 & Biaya listrik & 5.280 .000 \\
\hline 2 & $\begin{array}{l}\text { Biaya pemeliharaan } \\
\text { gudang (kontainer) }\end{array}$ & 750.000 \\
\hline 3 & Biaya tenaga kerja & 30.500 .000 \\
\hline & Jumlah & 36.530 .000 \\
\hline
\end{tabular}

Dari tabel di atas maka biaya penyimpanan per lembar dapat dihitung dengan rumus berikut:

$$
\begin{aligned}
& =\frac{\text { Total Biaya Persediaan }}{\text { Total Kebutuan bahan baku }} \\
& =\frac{R p 36.530 .000}{6791}=\operatorname{Rp~5.379,18}
\end{aligned}
$$

Jadi biaya penyimpanan per lembar film radiografi itu adalah $\mathrm{Rp} 5.379,18$

e) Total Biaya Persediaan

Maka total biaya persediaan (Total Inventory Cost) yang dapat dihitung sebagai berikut:

- Total kebutuhan bahan baku (D) $=6791$ lembar film

- Pembelian rata-rata bahan baku (Q) $=566$ lembar film 
- Biaya pemesanan untuk sekali pesan (S) = Rp 537.500,-

- Biaya penyimpanan per lembar $(\mathrm{H}) \quad=\mathrm{Rp} \quad 5.379,18$

Penghitungan total biaya persediaan (TIC) adalah:

$\mathrm{TIC}=\left[\frac{D}{Q} S\right]+\left[\frac{Q}{2} H\right]$

$\mathrm{TIC}=\left[\frac{6791}{566}(537.500)\right]+\left[\frac{566}{2}(5.379,18)\right]$

$\mathrm{TIC}=6.449 .050,35+1.522 .307,94$

$\mathrm{TIC}=7.971 .358,29$

Jadi total biaya persediaan yang harus ditanggung oleh perusahaan adalah sebesar Rp 7.971.358,29

\section{Analisis Dengan Metode EOQ}

a) Pembelian Bahan Baku yang Ekonomis

Dengan mengacu pada data-data berikut:

- Biaya penyimpanan bahan baku per lembar $(\mathrm{H}) \quad=\mathrm{Rp} \quad 5.379,18$

- Total kebutuhan bahan baku (D) =6791 lembar

- Biaya pemesanan untuk sekali pesan (S) = Rp 537.500,-

Maka besarnya pembelian bahan baku yang ekonomis (EOQ atau Q*)dapat dihitung dengan rumus sebagai berikut:

$$
\begin{aligned}
& \mathrm{Q}^{*}=\sqrt{\frac{2 D S}{H}} \\
& \mathrm{Q}^{*}=\sqrt{\frac{2(6791)(537.500)}{5.379,18}} \\
& \mathrm{Q}^{*}=\sqrt{\frac{7.300 .325 .000}{5.379,18}} \\
& \mathrm{Q}^{*}=\sqrt{1.357 .144,58} \\
& \mathrm{Q}^{*}=1164,96 \text { (dibulatkan menjadi } 1165 \text { lembar film radiografi) }
\end{aligned}
$$

b) Frekuensi Pemesanan Bahan Baku

Frekuensi pemesanan bahan baku menurut Metode EOQ dapat dihitung menggunakan rumus berikut:

$$
\begin{aligned}
& \mathrm{F}=\frac{D}{Q *} \\
& \mathrm{~F}=\frac{6791}{1165}=5,8 \text { kali (dibulatkan menjadi }=6 \text { kali) }
\end{aligned}
$$

c) Total Biaya Persediaan

Dalam menghitung total biaya persediaan (Total Inventory Cost) atau TIC, maka sebagaimana diketahui bahwa:

- Total Kebutuhan Bahan baku (D)

- Biaya pesan untuk sekali pesan (S)

- Biaya penyimpanan bahan baku per unit $(\mathrm{H})$

- Pembelian bahan baku yang ekonomis $\left(\mathrm{Q}^{*}\right)$

$$
\begin{aligned}
& =6791 \text { lembar } \\
& =\operatorname{Rp} 537.500,- \\
& =\operatorname{Rp} 5.379,18
\end{aligned}
$$$$
=1165 \text { lembar }
$$

Maka setelah dimasukkan kedalam rumus dan diolah sebagai berikut:

$$
\begin{aligned}
\text { TIC } & =\left[\frac{D}{Q} S\right]+\left[\frac{Q}{2} H\right] \\
\text { TIC } & =\left[\frac{6791}{1165}(537.500)\right]+\left[\frac{1165}{2}(5.379,18)\right]
\end{aligned}
$$


$\mathrm{TIC}=3.133 \cdot 186,70+3.133 .372,35$

$\mathrm{TIC}=6.266 .559,05$

Jadi total biaya persediaan yang dihitung menggunakan metode EOQ adalah sebesar Rp 6.266.559,05. Bila disimpulkan biaya ini masih lebih rendah dibandingkan dengan biaya aktual yang digunakan perusahaan dalam setahun yaitu $\operatorname{Rp} 7.971 .358,29$. Jadi ada sedikitnya Rp 1.704.799,24 lebih hemat dibandingkan dengan cara-cara biasa.

d) Penentuan Persediaan Pengaman (Safety Stock)

Hampir semua perusahaan pada umumnya mempunyai persediaan pengaman (safety stock) karena persediaan itu berfungsi untuk melindungi atau menjaga kemungkinan terjadinya kekurangan bahan baku pada saat produksi, atau juga yang dapat menghambat jadwal produksi. Dalam perhitungan persediaan pengaman, rata-rata bahan baku dengan pemakaian bahan baku sesungguhnya dibandingkan dan dicari penyimpangannya dengan standar deviasi sebagaimana Tabel 4 berikut.

Tabel 4. Perhitungan Standar Deviasi

\begin{tabular}{|l|c|c|c|c|}
\hline \multicolumn{1}{|c|}{ Bulan } & $\begin{array}{c}\text { Kebutuhan } \\
\text { Bahan Baku }\end{array}$ & $\overline{\boldsymbol{X}}$ & $(\mathbf{X}-\overline{\boldsymbol{X}})$ & $(\mathbf{X}-\overline{\boldsymbol{X}})^{\mathbf{2}}$ \\
\hline Januari & 331 & 565,91 & $-234,91$ & 55182,7 \\
\hline Februari & 1292 & 565,91 & 726,09 & 527206,68 \\
\hline Maret & 584 & 565,91 & 18,09 & 327,25 \\
\hline April & 1056 & 565,91 & 490,09 & 240188,21 \\
\hline Mei & 987 & 565,91 & 421,09 & 177316,8 \\
\hline Juni & 211 & 565,91 & $-354,91$ & 125961,11 \\
\hline Juli & 112 & 565,91 & $-453,91$ & 206034,3 \\
\hline Agustus & 413 & 565,91 & $-152,91$ & 23381,47 \\
\hline September & 148 & 565,91 & $-417,91$ & 174648,77 \\
\hline Oktober & 259 & 565,91 & $-306,91$ & 94193,75 \\
\hline November & 673 & 565,91 & 107,09 & 11468,27 \\
\hline Desember & 725 & 565,91 & 159,09 & 25309,63 \\
\hline Jumlah & 6791 & & & 1661218,94 \\
\hline
\end{tabular}

$$
\begin{gathered}
\bar{X}=\frac{D}{n}=\frac{6791}{12 \text { bulan }}=565,91 \\
\mathrm{SD}=\sqrt{\frac{\sum(X-\bar{X})^{2}}{n}} \\
\mathrm{SD}=\sqrt{\frac{1661218,94}{12}} \\
\mathrm{SD}=\sqrt{138434,91}=372,07
\end{gathered}
$$

Dengan pemakaian asumsi bahwa perusahaan menerapkan persediaan yang memenuhi permintaan $95 \%$ dan persediaan cadangan 5\%, sehingga dapat diperoleh $\mathrm{Z}$ dengan tabel normal sebesar 1,65 deviasi standar di atas rata-rata.

$$
\begin{aligned}
\text { Safety stock } & =\mathrm{SD} \times \mathrm{Z} \\
& =372,07 \times 1,65 \\
& =813,92 \text { (dibulatkan menjadi } 814 \text { lembar film radiografi) }
\end{aligned}
$$


Jadi persediaan bahan pengaman (safety stock) perusahaan adalah sebanyak 814 lembar film radiografi.

e) Pemesanan kembali (Re-order Point)

Waktu tunggu (lead time) yang diperlukan perusahaan untuk menunggu datangnya bahan baku yang telah dipesan rata-rata 3 hari. Waktu yang paling cepat adalah 2 hari dan paling lama adalah 4 hari. Dengan rata-rata jumlah hari kerja 300 hari kerja dalam setahun, maka dapat dihitung Re-order point-nya dengan cara berikut.

Pertama mencari dulu tingkat penggunaan bahan baku per hari (U)

$$
\begin{aligned}
& \mathrm{U}=\frac{D}{t} \\
& \mathrm{U}=\frac{6791}{300} \\
& \mathrm{U}=22,64 \text { (dibulatkan menjadi } 23 \text { lembar film perhari) }
\end{aligned}
$$

Maka titik pemesanan kembali (Re-order point= ROP) adalah:

$$
\begin{aligned}
\mathrm{ROP} & =(\mathrm{U} \times \mathrm{L})+\mathrm{SS} \\
& =(23 \times 3)+814 \\
& =883 \text { lembar film radiografi }
\end{aligned}
$$

\section{Perbandingan antara cara perusahaan dan Metode EOQ}

Perbandingan antara kondisi sekarang yang dilakukan perusahaan dengan menggunakan metode EOQ dapat diperoleh dalam tabel berikut (Tabel 5), dan dalam tabel itu didapati bahwa dengan menggunakan metode EOQ dapat diperoleh hasil yang lebih efisien.

Tabel 5. Perbandingan antara Kondisi Sekarang dengan metode EOQ

\begin{tabular}{|c|l|c|c|}
\hline No & \multicolumn{1}{|c|}{ Keterangan } & Kondisi Sekarang & Metode EOQ \\
\hline 1 & $\begin{array}{l}\text { Pembelian rata-rata bahan baku (lembar } \\
\text { film radiografi) }\end{array}$ & 566 & 1165 \\
\hline 2 & Total Biaya Persediaan (TIC) dalam Rp & $7.971 .358,29$ & $6.266 .559,05$ \\
\hline 3 & Frekuensi Pemesanan (kali) & 12 & 6 \\
\hline 4 & Safety Stock (lembar film) & - & 814 \\
\hline 5 & Re-order point (lembar film) & - & 883 \\
\hline
\end{tabular}

\section{KESIMPULAN}

Berdasarkan analisis data di atas maka peneliti dapat menyimpulkan sebagai berikut:

a) Pembelian rata-rata dapat dioptimasikan sesuai dengan metode EOQ yaitu 1165 lembar film per sekali pesan, hal ini dilakukan agar total biaya persediaan dapat ditekan atau dibuat minimum. Kondisi sekarang dari total biaya persediaan (TIC) adalah Rp 7.971.358,29 sedangkan dengan menggunakan metode EOQ, TIC berkurang menjadi Rp 6.266.559,05 sehingga ada penghematan biaya sebesar Rp 1.704.799,24 dalam setahun bagi perusahaan.

b) Dengan metode EOQ juga dapat ditentukan bahwa frekuensi pemesanan dapat dilakukan sebanyak 6 kali, Safety stock sebesar 814 lembar film dan titik pemesanan kembali sebanyak 883 lembar film.

\section{SARAN}

Saran yang diajukan penulis sebagai bahan pertimbangan kepada perusahaan adalah:

a) Perusahaan hendaknya mempertimbangkan akan penggunaan metode EOQ dalam melakukan pemesanan bahan baku (film radiografi), agar perusahaan dapat menekan biaya secara minimal dan meningkatkan keuntungan perusahaan. 
b) Perusahaan menggunakan Safety Stock dan Re-order point sebagai langkah-langkah pengamanan produksi dan agar tidak terjadi back log dalam pelayanan produksi ke pelanggan.

c) Perusahaan perlu melakukan brain storming, bench marking dan pelatihan-pelatihan yang dapat meningkat skill dan motivasi karyawan dan meningkatkan produktivitas.

\section{UCAPAN TERIMA KASIH}

Ucapan terima kasih kepada PT Hitek Indo Mulia yang telah bersedia mengizinkan penulis melakukan penelitian di perusahaan, dan kepada Bapak H Raden Erwin sebagai pemilik perusahaan dan kepada manajer dan seluruh jajaran perusahaan. Ucapan terima kasih juga kepada Bapak Direktur Pasca Sarjana Universitas Riau Kepulauan, Bapak Dr. Lukmanul Hakim, SE, M.Si, kepada Ketua Program Studi Magister Manajemen, kepada para Dosen dan civitas Universitas Riau Kepulauan Program Studi Magister Manajemen.

\section{DAFTAR PUSTAKA}

Apriyani N, Muhsin A. 2017. Analisis Pengendalian Persediaan Bahan Baku Dengan Metode Economic Order Quantity dan Kanban Pada PT Adyawinsa Stamping Industries. 10(2):128-142.

Carter W K. 2009. Akutansi Biaya Jilid 1, Edisi ke-14. Jakarta. Salemba Empat.

Handoko T, Hani. 2000. Dasar-Dasar Manajemen Produksi dan Operasi. Yogyakarta. BPFE.

Herjanto E. 2008. Manajemen Operasi. Edisi Ke-3. Jakarta. PT Grasindo.

Herjanto E. 2009. Sains Manajemen - Analisis Kuantitatif untuk Pengambilan Keputusan. Jakarta. PT Grasindo.

Herlambang A I P, Dewi R. 2017. Pengendalian Persediaan Bahan Baku Beras Dengan Metode Economic Order Quantity (EOQ) Multi Produk Guna Meminimumkan Biaya. Studi Kasus pada CV Lumbung Tani Sejahtera. Jurnal Ekonomi \& Bisnis, JEB 17. 2(2):525-542.

Johns D T, Harding H A. 1996. Manajemen Operasi. Jakarta. PT Pustaka Binaman Pressindo. Kusuma H. 2009. Manajemen Produksi: Perencanaan dan Pengendalian Produksi. Edisi Ke4. Yogyakarta. Penerbit Andi.

Prawirosentono S. 2005. Riset Operasi dan Ekonofisika. Jakarta. PT Bima Aksara.

Rangkuti F. 2007. Manajemen Persediaan. Jakarta. Rajawali Pers.

Render B, Heizer J. 2010. Manajemen Operasi. Edisi Ke-9. Buku 2. Jakarta. Salemba Empat.

Schroeder R. 1995. Pengambilan Keputusan Dalam Suatu Fungsi Operasi. Edisi Ke-3. Jakarta. Erlangga.

Susanti L, Machfud, Hasbullah R. 2015. Pengendalian Persediaan Bahan Baku Base Material Pada Industri Keramik Di PT XYZ. Jurnal Aplikasi Bisnis dan Manajemen. 1(2):108117. 